\title{
Prosthesis-patient mismatch after mitral valve replacement: a single-centered retrospective analysis in East China
}

\author{
Armah M Akuffu, Haige Zhao, Junnan Zheng ${ }^{*}$ and Yiming $\mathrm{Ni}$
}

\begin{abstract}
Background: Prosthesis-patient mismatch (PPM) may affect the clinical outcomes of patients undergoing mitral valve replacement (MVR) surgery. We aimed to investigate the incidence of PPM of the mitral position in our center and analyze the possible predictors of PPM as well as its effect on short-term outcomes.

Methods: We retrospectively examined all consecutive patients with isolated or concomitant MVR at our center from 2013 to 2015. PPM was defined as an indexed effective orifice area (iEOA) of $\leq 1.2 \mathrm{~cm} 2 / \mathrm{m} 2$. After inclusion and exclusion, a total of 1067 patients were analyzed. The baseline information were collected and compared between the two groups. Multivariate logistic regression analysis was conducted to determine the preoperative predictors of PPM as well as the effect of PPM on early mortality.
\end{abstract}

Results: A total of 1067 patients were included in the study. PPM was detected in 15.9\% of the patients while 12 patients (1.12\%) met the criteria for severe PPM. Patients with PPM compared to the non-PPM patients had higher age, larger body surface area and were more likely to be male and obese. Logistic regression analysis showed that higher age, larger BSA, bioprosthesis and smaller left ventricle end-diastolic diameter were predictors of PPM. There were no significant differences between the PPM and non-PPM groups regarding post-operative complications. Logistic regression analysis showed that PPM was not a risk factor of short-term mortality $(P=0.654)$. Also, there were no significant differences regarding short-/mid-term heart function between the PPM and non PPM groups $(P=0.902)$.

Conclusions: Our results demonstrated that higher age, bioprosthesis, larger BSA and smaller left ventricle size were associated with mitral PPM. However, PPM was not associated with poorer early outcomes after MVR surgery. In eastern of China, the prevalence of mitral valve stenosis is high; therefore, whether the standard PPM criteria are suitable for patients of this district needs to be further verified.

Keywords: Prosthesis-patient mismatch, Mitral valve replacement, Effective orifice area, Short-term mortality

\section{Background}

The phenomenon of prosthesis-patient mismatch (PPM) was initially described by Rahimtoola and Murphy about 40 years ago $[1,2]$. Currently, PPM is considered a condition in which the effective orifice area (EOA) of the implanted valve prosthesis does not match the patient's body size.

PPM of the aortic position has been proved to be associated with poorer outcomes including long- and

\footnotetext{
* Correspondence: zhengjunnan@zju.edu.cn

Department of Cardiothoracic Surgery, the First Affiliated Hospital of Zhejiang University, No.79 Qingchun Road, Hangzhou 310003, China
}

short-term cardiac death [3-5]. However, PPM following mitral valve replacement (MVR) has still been less investigated.

In recent years, PPM after MVR has attracted more and more attention from researchers. Researches has shown that the EOA of mitral valve prosthesis is often too small in relation to body size, thus, normally functioning mitral prosthesis often has relatively high transvalvular gradients similar to those found in mild to moderate mitral valve stenosis patients [6-10].

In East Asia, where rheumatic mitral valve stenosis is very common, the mitral valve annulus in patients is

(c) The Author(s). 2018 Open Access This article is distributed under the terms of the Creative Commons Attribution 4.0 International License (http://creativecommons.org/licenses/by/4.0/), which permits unrestricted use, distribution, and 
relatively small; therefore more patients meet the standard of mitral PPM [11]. We aim to investigate the incidence of PPM of the mitral position in our center and analyze the possible predictors of PPM as well as its effect on short-term outcomes. We will also discuss the eligibility of the current PPM standard for this population.

\section{Methods}

\section{Patient population and data collection}

We retrospectively reviewed all consecutive patients who underwent elective isolated or concomitant MVR at our center, the Department of Cardiothoracic Surgery, the First Affiliated Hospital, Zhejiang University, School of Medicine, from January 2013 to December 2015. Written informed consent waivers obtained from the Hospital Review Board were completed by all patients.

We analyzed all consecutive patients aged more than 18 years undergoing isolated MVR or MVR concomitant with other non-valve-replacement procedures. Patients with incomplete clinical data or patients who received MVR due to failed mitral valvuloplasty were excluded (Fig. 1).

In total, 1067 patients were included in this study. Baseline, intraoperative and outcome data were prospectively collected and validated, which were queried retrospectively. 30-month postoperative follow-up was conducted for discharged patients at the outpatient clinic. Patients who did not show up at the visit were contacted by telephone.

\section{PPM definition and EOA index (EOAi) calculation}

Body surface area (BSA) of the patients was calculated using the Dubois formula. The EOA of the mitral valve prosthesis was derived from in vitro measurements provided by the manufacturers and from scientific publications, as outlined in Table 1.

EOAi (also called indexed effective orifice area, iEOA) was obtained with EOA divided by BSA. Mitral PPM was defined as EOAi $\leq 1.2 \mathrm{~cm}^{2} / \mathrm{m}^{2}$. EOAi $\leq 0.9 \mathrm{~cm}^{2} / \mathrm{m}^{2}$ was considered severe mitral PPM.

Other definitions were listed as follows. Chronic renal insufficiency: serum creatinine $\geq 2 \mathrm{mg} / \mathrm{dl}$. Peripheral arterial disease: claudication, carotid stenosis $>50 \%$ or previous/planned intervention on the abdominal aorta, limb arteries or carotids. Coronary artery disease: $\geq 50 \%$ reduction in one or more coronary vessels in single or multiple plane angiographic images. Emergency surgery: operation required within $24 \mathrm{~h}$ of onset of symptoms. Postoperative renal failure: increase in baseline creatinine greater than $2 \mathrm{mg} / \mathrm{dl}$.

\section{Surgical technique and prosthesis application}

The operation records of all patients were reviewed. A total of 868 mechanical valve prostheses and 199 bioprostheses were implanted. The following prostheses were used in as followings:

Mechanical prosthesis: CarboMedics Orbis Universal (CarboMedics, Inc., Austin, TX, USA) $(n=679)$; St Jude Master (St Jude Medical, Inc., St Paul, MN, USA) $(n=$ 154); ATS open pivot (ATS Medical, Inc., Minneapolis,

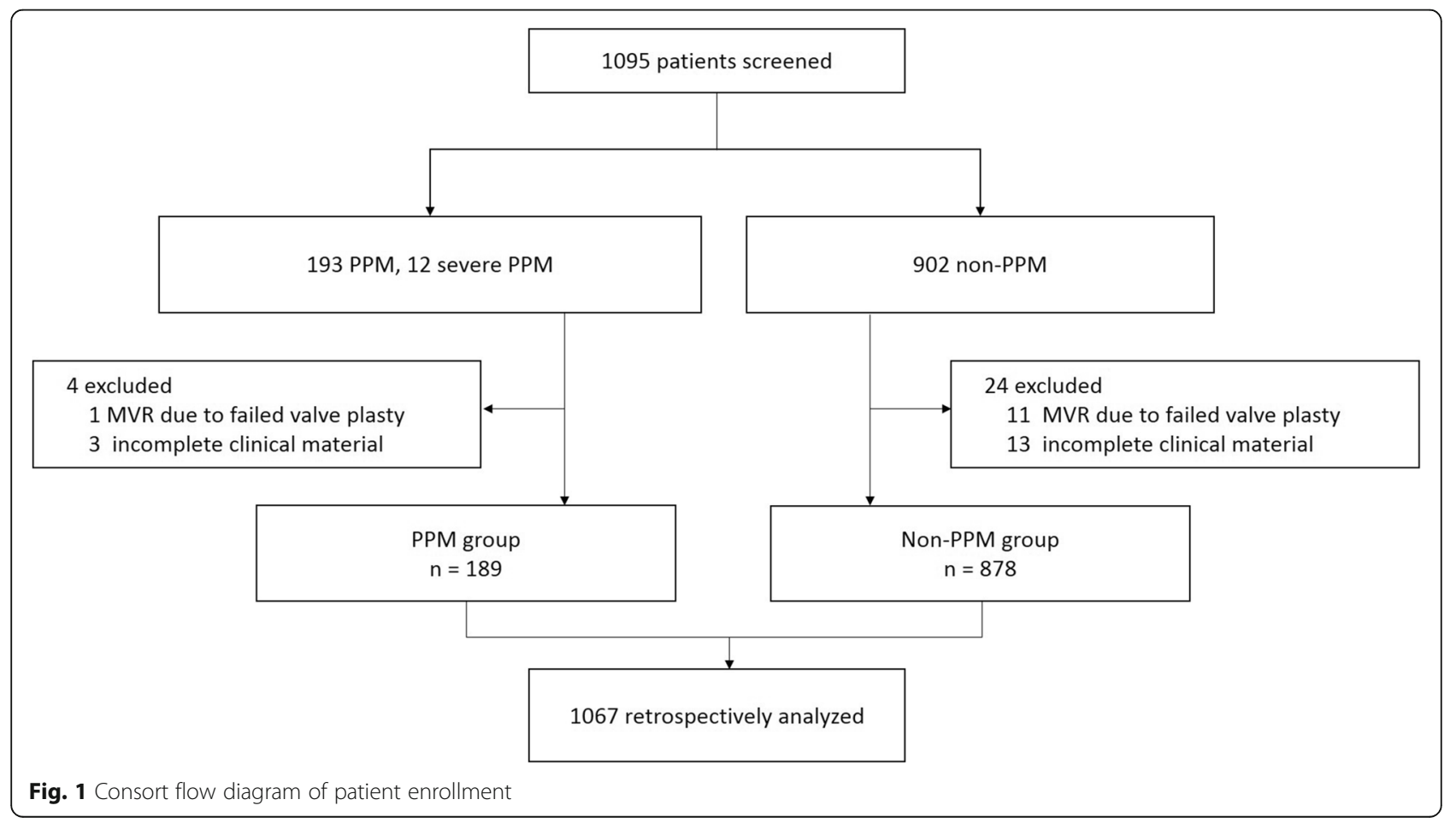


Table 1 In vivo effective orifice area values $\left(\mathrm{cm}^{2}\right)$ corresponding to each valve

\begin{tabular}{|c|c|c|c|c|c|c|c|c|}
\hline Valve prosthesis & patients & $23 \mathrm{~mm}$ & $25 \mathrm{~mm}$ & $27 \mathrm{~mm}$ & $29 \mathrm{~mm}$ & $31 \mathrm{~mm}$ & $33 \mathrm{~mm}$ & Ref \\
\hline Mechanical & 868 & & & & & & & \\
\hline CarboMedics Orbis Universal & 680 & 1.8 & 2.2 & 2.2 & 2.4 & 2.4 & 2.3 & [12] \\
\hline St.Jude Master series & 154 & 1.0 & 1.5 & 1.8 & 1.8 & 2.0 & 2.0 & {$[13,21]$} \\
\hline ATS open pivot & 33 & - & 1.8 & 2.8 & 2.8 & 2.9 & 2.9 & [22] \\
\hline Bioprosthesis & 199 & & & & & & & \\
\hline Medtronics Hancock II & 110 & - & 1.5 & 1.8 & 1.9 & 2.6 & 2.6 & [12] \\
\hline Medtronics Mosaic & 5 & - & 1.5 & 1.7 & 1.9 & 1.9 & - & [13] \\
\hline St. Jude Bicor Stented & 45 & - & 1.4 & 1.5 & 2.3 & 2.2 & 2.3 & [23] \\
\hline Carpentier-Edwards perimount & 39 & - & 1.7 & 1.9 & 2.3 & 2.8 & 2.7 & [12] \\
\hline
\end{tabular}

MN, USA) ( $n=33)$; Bioprosthesis: Hancock II Porcine Bioprosthesis (Medtronic, Inc., Minneapolis, MN, USA) $(n=110)$; Mosaic Porcine Bioprosthetic Valves (Medtronic, Inc., Minneapolis, MN, USA) $(n=5)$; Bicor Stented Bioprosthesis (St Jude Medical, Inc., St Paul, MN, USA) $(n=45)$; Carpentier-Edwards perimount (Baxter Healthcare Corp., Edwards Division, Santa Ana, CA, USA) $(n=39)$.

An isolated or concomitant MVR was performed in all patients. Concomitant procedures included tricuspid valvuloplasty, coronary artery bypass grafting, atrial septum defect repair and/or other procedures. Standard anesthesia and cardiopulmonary bypass methods were implemented. Most of the patients were approached through a full median sternotomy followed by an antegrade 4:1 cold blood cardioplegia for myocardial protection. Antegrade plus retrograde cardioplegia was applied for patients with coronary stenosis. Intermittent perfusion of cold blood cardioplegia was maintained at a frequency of once every $20 \mathrm{~min}$.

After consulting with the patients preoperatively, the final decision of the type of prosthesis was made by the surgeons during operation, taking into consideration the preoperative information and intraoperative findings. When performing the MVR, sub-valvular structures were preserved as much as possible.

\section{Statistical analysis}

The Kolmogorov-Smirnov test was used to verify the distribution of all the quantitative variables. Gaussian distributed continuous variables were presented as mean \pm standard deviation (SD), while non-Gaussian distributed variables were presented as medians (interquartile range). Categorical variables were expressed as an absolute number (percentage). Pearson's $x^{2}$ test was used for descriptive, univariate statistics, such as the comparison of portions, while the Student's unpaired $t$-test was used for normally distributed data comparisons. Otherwise, the Mann-Whitney $U$ test was otherwise used for comparison of non-Gaussian distributed variables. Two-tailed
$P$-values were derived from the calculated test statistics, and $P \leq 0.05$ was considered statistically significant. Binary multivariate logistic regression analysis was performed to study the factors affecting PPM as well as mortality. IBM SPSS Statistics 20.0 software (IBM, Armonk, NY, USA) was used to analyze the data.

\section{Results}

Preoperative data and baseline information

A total of 1067 patients were included in this study. Mitral PPM was detected in $17.71 \%(189 / 1067)$ of the patients and only $12(1.12 \%)$ patients met the criteria for severe PPM.

Compared with the non-PPM group, patients with PPM were older, taller and heavier and had a higher prevalence of male gender, hypertension, smoking history, coronary heart disease, and had a lower prevalence of mitral stenosis (Table 2).

\section{Patient characterize, PPM and valve prosthesis size}

We analyzed the association among age, weight, height, BSA and valve size (Fig. 2). Krusal-Wallis analysis showed that weight, height and BSA are significantly associated with valve size $(P<0.01)$. In summary, larger mitral bioprosthetic valves were implanted in the taller and more obese patients.

Also, the PPM rate of each size of the prostheses was analyzed (Fig. 3). The results showed that the PPM rate of mechanical valve prostheses was considerably lower compared with bioprostheses $(10.6 \%$ vs $48.5 \%$, respectively, $P<0.001)$. As for the mechanical prostheses, there were no significant differences regarding the PPM occurrence of each valve size, whereas, the PPM rate of the $25 \mathrm{~mm}$ bioprosthesis was higher than that of the $27 \mathrm{~mm}$ and $29 \mathrm{~mm}$ bioprostheses $(P<0.01)$.

On the other hand, the PPM rate also differed among different brands of prostheses. As for mechanical prostheses, according to our data, PPM rate was highest $(55.8 \%, 86 / 154)$ in patients underwent MVR with 
Table 2 Preoperative patient baseline information

\begin{tabular}{|c|c|c|c|c|}
\hline preoperative information & $\begin{array}{l}\text { total } \\
(n=1067)\end{array}$ & $\begin{array}{l}\text { PPM group } \\
(n=189)\end{array}$ & $\begin{array}{l}\text { non-PPM group } \\
(n=878)\end{array}$ & $P$ value \\
\hline Age, y & $56(48-62)$ & $63(55-67)$ & $54(46-61)$ & $<0.001$ \\
\hline Male & $379(35.5 \%)$ & $89(47.1 \%)$ & $290(33.0 \%)$ & $<0.001$ \\
\hline Height, cm & $160.72 \pm 7.82$ & $163.26 \pm 7.87$ & $160.17 \pm 7.71$ & $<0.001$ \\
\hline Weight, kg & $57.72 \pm 10.33$ & $62.42 \pm 10.23$ & $56.70 \pm 10.07$ & $<0.001$ \\
\hline BMl, $\mathrm{kg} / \mathrm{m}^{2}$ & $22.29 \pm 3.67$ & $23.34 \pm 2.86$ & $22.07 \pm 3.79$ & $<0.001$ \\
\hline $\mathrm{BSA}, \mathrm{m}^{2}$ & $1.57 \pm 0.16$ & $1.64 \pm 0.17$ & $1.55 \pm 0.16$ & $<0.001$ \\
\hline Smoking history & $123(11.5 \%)$ & $32(16.9 \%)$ & $91(10.4 \%)$ & 0.016 \\
\hline Diabetes & $102(9.6 \%)$ & $22(11.6 \%)$ & $80(9.2 \%)$ & NS \\
\hline Hypertention & $192(18.0 \%)$ & $47(24.9 \%)$ & $145(16.5 \%)$ & 0.009 \\
\hline Cerebrovascular accident & $34(3.2 \%)$ & $6(3.2 \%)$ & $28(3.2 \%)$ & NS \\
\hline Coronary heart disease & $22(2.1 \%)$ & $9(4.8 \%)$ & $13(1.5 \%)$ & 0.009 \\
\hline NYHA functional class ( $\geq$ III) & $400(37.5 \%)$ & $77(40.7 \%)$ & $323(36.8 \%)$ & NS \\
\hline Atrial fibrillation & $533(50.0 \%)$ & $92(48.7 \%)$ & $441(50.2 \%)$ & NS \\
\hline Previous cardiac surgery & $54(5.1 \%)$ & $8(4.2 \%)$ & $46(5.2 \%)$ & NS \\
\hline Previous Ml & $1(0.1 \%)$ & $0(0.0 \%)$ & $1(0.1 \%)$ & NS \\
\hline Mitral stenosis & $786(76.7 \%)$ & $128(67.7 \%)$ & $658(74.9 \%)$ & 0.036 \\
\hline MR (moderate to severe) & $470(44.0 \%)$ & $88(46.5 \%)$ & $382(43.5 \%)$ & NS \\
\hline LVEF & $62.11 \pm 8.48$ & $62.23 \pm 8.95$ & $62.09 \pm 8.38$ & NS \\
\hline $\mathrm{LVdD}, \mathrm{mm}$ & $50(45-56)$ & $51(46-58)$ & $50(45-56)$ & NS \\
\hline $\mathrm{LAD}, \mathrm{mm}$ & $51.36 \pm 12.04$ & $51.36 \pm 11.93$ & $51.36 \pm 12.07$ & NS \\
\hline Emergency surgery & $2(0.2 \%)$ & $0(0.0 \%)$ & $0(0.0 \%)$ & NS \\
\hline Aspirin within 5 days & $29(2.7 \%)$ & $9(4.8 \%)$ & $20(2.3 \%)$ & NS \\
\hline Clopidogrel within 5 days & 19(1.8\%) & $6(3.2 \%)$ & $13(1.5 \%)$ & NS \\
\hline
\end{tabular}

BMI body mass index, BSA body surface area, NYHA New York Heart Association, MI myocardial infarction, MR mitral valve regurgitation, $L V E F$ left ventricular ejection fraction, $L V d D$ left ventricular diastolic diameter, $L A D$ left atrial diameter, NS not significant

St. Jude Master Mechanical prostheses. And PPM rate was considerably low regarding CarboMedics mechanical prosthesis $(0.9 \%, 6 / 679)$ and ATS open pivot mechanical prostheses $(0.0 \%, 0 / 33)$. As for bioprosthesis, our results showed that PPM rate was high in patients using Medtronic Mosaic porcine bioprosthesis $(80.0 \%, 4 / 5)$ or St. Jude Bicor bioprosthesis (82.2\%, 37/45), whereas patients underwent MVR with Carpentier-Edwards Perimount bioprosthesis (17.7\%, 5/38) and Medtronic Hancock II (45.4\%, 50/110) showed lower rate of PPM.

\section{Operative data}

As shown in Table 3, there were no significant differences between PPM and non-PPM patients regarding cardiopulmonary bypass $(\mathrm{CPB})$ time. However, we found that there is an average five-minute cross-clamp time reduction in the PPM group.

Not surprisingly, remarkably more patients with a PPM were implanted with a bioprosthetic mitral valve. And as for patients who received a bioprosthesis, the prevalence of mitral stenosis was higher for mismatch patients $(58.3 \%$ vs $41.7 \%, P=0.019)$, whereas patients of mechanical prostheses did not differ in the prevalence of mitral stenosis, whether PPM or not $(77.4 \%$ vs $79.4 \%$, $P>0.05)$.

As for combined procedures, there were more combined coronary artery bypass grafting (CABG) and surgical ablation for atrial fibrillation in the PPM group.

\section{Factors affecting PPM}

According to a multivariate binary logistic regression analysis including all preoperative and intraoperative variables, higher age $(P=0.011)$, larger BSA $(P<0.001)$, smaller left ventricular diastolic diameter (LVDd) $(P<$ $0.001)$ and bioprosthesis $(P<0.001)$ were factors affecting mitral PPM (Table 4).

\section{Postoperative outcomes and factors affecting postoperative mortality}

There were no obvious differences between the two groups regarding early post-operative complications including blood transfusion, ventilation time, reintubation, intensive care unit (ICU) time, postop stroke, postop 

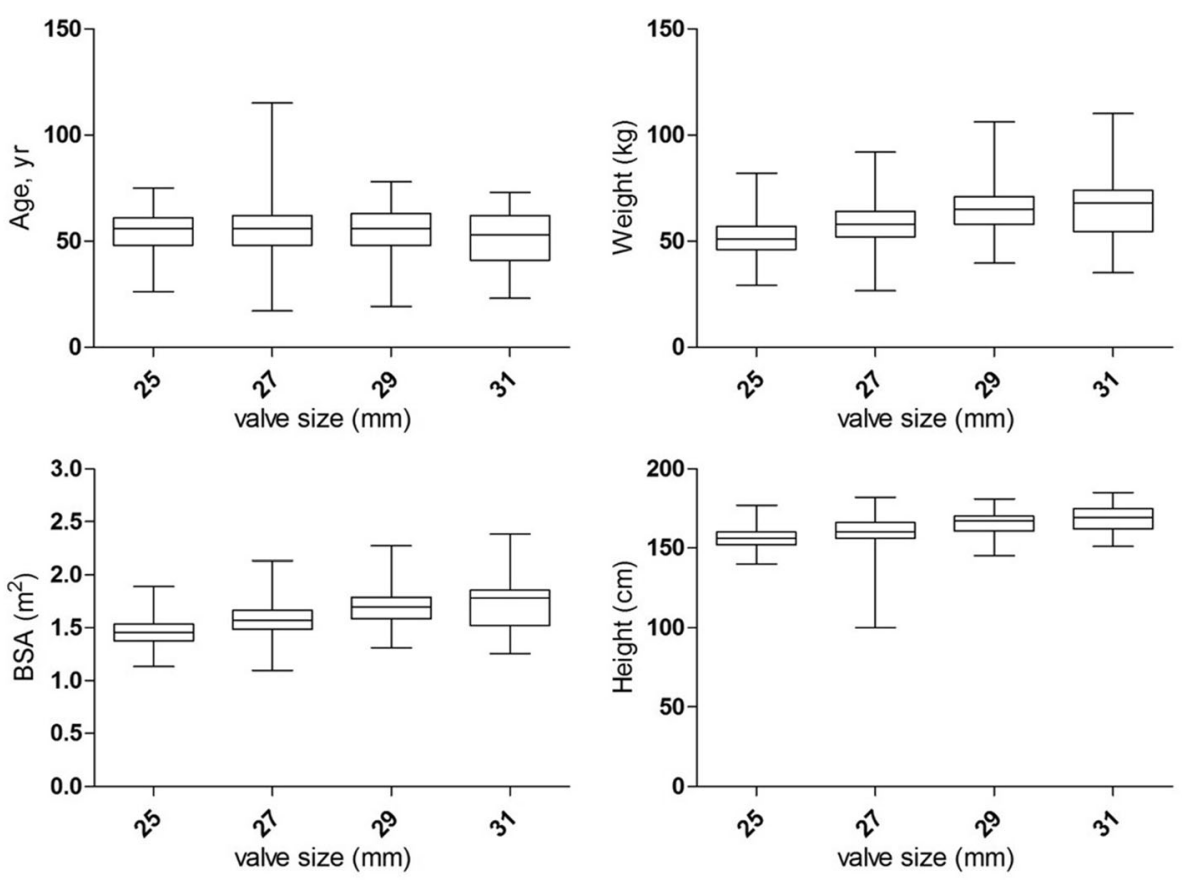

Fig. 2 Boxplot showing distribution of age (NS), weight $(P<0.01)$, height $(P<0.01)$, and body surface area $(P<0.01)$, respectively, according to aortic valve size implanted

atrial fibrillation and short-term mortality. Also, there were no other reoperation for valve-rated complications including PPM or other cardiac disease during hospital-stay except that two patients underwent emergency percutaneous coronary intervention for acute myocardium ischemia. Interestingly, we found that there was a small increase in hospitalization expense as well as a slightly prolonged hospital stay for the PPM patients (Table 5).

Altogether there were nine patients died within 30 days after surgery. Among them, five patients died due to malignant arrhythmia or cardiac arrest, two patient died of sever systematic infection, one patient died of uncontrollable bleeding and one patient died because of stroke. Among these short-term deaths, 2 patients underwent

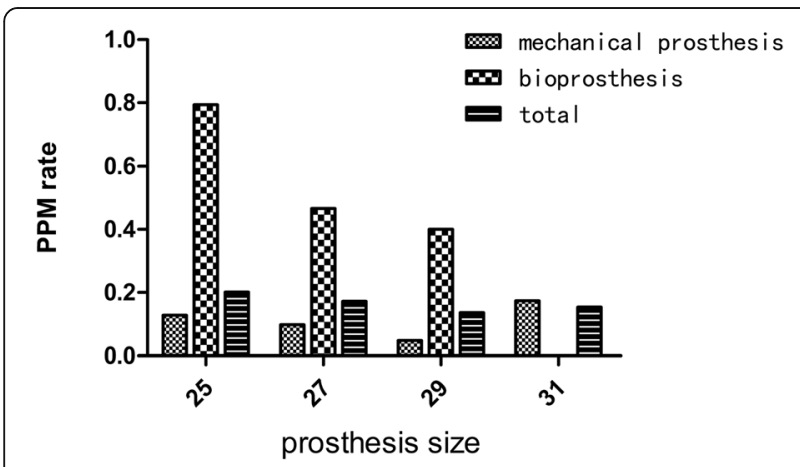

Fig. 3 The PPM rate of each valve size for bioprostheses and mechanical prostheses respectively
MVR with Hancock II bioprostheses, whereas 7 patients were replaced with CarboMedics mechanical prostheses.

Logistic regression analysis showed that smoking history and preoperative low left ventricular ejection fraction (LVEF) were independent factors predicting post-operative short-term all-cause mortality. However, PPM was not a risk factor for short-term mortality (Table 6).

\section{Mid-term follow-up}

During mid-term follow-up, two patients underwent re-operative for stuck of the mechanical prostheses (both CarboMedics Mechanical prostheses). Both of the patients had an irregular medication history of Warfarin.

Mid-term deaths occurred in eight patients who all underwent MVR with a mechanical prosthesis, adding to the previously mentioned nine short-term deaths. Cumulative mid-term overall survival is 0.986 for both PPM and non-PPM patients (Fig. 4), and there were no significant difference regarding mid-term mortality for the two groups (SE 0.037, Log-rank $p=0.847$ ). All the later occurring eight deaths were coagulation-related death. The overall mortality at 30 months was approximately $1.6 \%$ (Table 7). During follow-up, about $9.2 \%$ of the patients presented compromised cardiac functions with New York Heart Association (NYHA) functional classes III to IV. However, there were no significant differences between the PPM and non-PPM patients. 
Table 3 Intraoperative data

\begin{tabular}{|c|c|c|c|c|}
\hline & total & $\begin{array}{l}\text { PPM group } \\
n=189\end{array}$ & $\begin{array}{l}\text { non-PPM group } \\
n=878\end{array}$ & $P$ value \\
\hline First time surgery & $1013(94.9 \%)$ & $181(95.8 \%)$ & 832(94.7\%) & NS \\
\hline CPB time (min) & 83(70-92) & 83(70-89) & 83(70-93) & NS \\
\hline Cross-clamp time (min) & $50(41-62)$ & $45(40-55)$ & $50(41-63)$ & $<0.001$ \\
\hline Bioprosthesis & 199(18.7\%) & $96(50.8 \%)$ & $103(11.7 \%)$ & $<0.001$ \\
\hline \multicolumn{5}{|l|}{ Combined procedure } \\
\hline Tricuspid valve plasty & $277(26.0 \%)$ & $38(20.1 \%)$ & $239(27.2 \%)$ & NS \\
\hline CABG & $28(2.6 \%)$ & $11(5.8 \%)$ & $17(1.9 \%)$ & 0.005 \\
\hline AFRA or Maze surgery & $106(9.9 \%)$ & $30(15.9 \%)$ & $76(8.7 \%)$ & 0.005 \\
\hline Others & 139(13.0\%) & $30(15.9 \%)$ & $109(12.4 \%)$ & NS \\
\hline
\end{tabular}

CPB cardiopulmonary bypass, CABG coronary artery bypass grafting surgery, AFRA atrial fibrillation radio frequency surgery, NS not significant

\section{Discussion}

\section{PPM occurrence and its risk factors}

Although highly variable, PPM rates for mitral position in most of the literature ranged from 20 to $70 \%$ [11-16]. However, the incidence of PPM after MVR in our single-centered cohort was $17.7 \%$ and only $1.2 \%$ of the cases met the criteria for severe PPM.

We performed logistic regression analysis and found that larger BSA, higher age, implantation of bioprosthesis and smaller LVDd were risk factors for PPM. Besides BSA, EOA was the only variable defining the EOAi which determined the occurrence of PPM. Bioprosthesis possessed smaller EOA compared with mechanical prosthesis of the same valve size, leading to an increased rate of PPM. Also, bioprostheses were more prone to late degenerative calcification, which may further decrease its EOA. Thus, the more common use of bioprosthesis for degenerative mitral regurgitation might explain the lower prevalence of mitral stenosis of the PPM group in the preoperative data. As for LVDd, it was an indirect reflection of the mitral annulus diameter, which was another decisive factor in choosing prosthesis size, affecting the EOA of the prosthesis implanted. Higher age was then associated with more bioprosthesis implantation, thus leading to the increase in PPM occurrence. Hence, the difference of patient baseline characteristics between the PPM and non-PPM patients in hypertension and coronary heart disease could be explained by the higher age and obesity of the PPM patients.

Table 4 Logistic regression analysis for prosthesis-patient mismatch

\begin{tabular}{lllll}
\hline Factors & mean or $\%$ & OR & $95 \% \mathrm{Cl}$ & $P$ value \\
\hline Age & 54 & 1.029 & $1.006-1.051$ & 0.011 \\
BSA $\left(\mathrm{m}^{2}\right)$ & 1.57 & 152.111 & $45.261-511.208$ & $<0.001$ \\
LVDd $(\mathrm{mm})$ & 51.26 & 0.964 & $0.944-0.984$ & $<0.001$ \\
bioprosthesis & $18.7 \%$ & 7.539 & $4.632-12.273$ & $<0.001$ \\
\hline $\begin{array}{l}\text { OR odds ratio, Cl confidence interval, BSA body surface area, LVDd left } \\
\text { ventricular diastolic diameter }\end{array}$
\end{tabular}

In the Asian population, especially the eastern Chinese population, mitral stenosis and small size mitral prosthesis implantation might generally be considered to occur more frequently than in Western populations due to rheumatic causes associated with a small annulus. However, due to rheumatic etiology, the episode age of these patients was considerably younger than patients with valvular degeneration as predominant causes in Western countries. Thus, a larger ratio of patients of this population were implanted with mechanical mitral prostheses which possessed larger EOA than bioprosthesis. Also, patients of this population had a smaller body surface area than those in Western populations, leading to a further reduction in PPM occurrence. The aforementioned factors altogether help explain the low PPM rate in our study population.

\section{PPM and patient outcomes}

Since its first description in 1978 by Rahimtoola [1], PPM after MVR has been suggested to potentially correlate with poor clinical outcomes including late tricuspid regurgitation and persistent pulmonary hypertension $[11,14,17]$, similar to the outcomes of residual mitral stenosis. However, there were also reports suggesting that PPM did not affect survival after MVR $[18,19]$.

In our analysis, no impact of PPM on patient mortality was detected either in the postoperative short-term period or in the mid-term follow-up. Our findings are consistent with several large sample multi-centered analyses $[15,19]$. Our results showed that smoking history and low preoperative LVEF were associated with higher short-term mortality, but not PPM.

Interestingly, our study showed that cross-clamp times were shorter in patients with PPM, with an average shortened time of $5 \mathrm{~min}$. This might be explained because less time was spent suturing the mitral prosthesis due to the smaller mitral annulus diameter of the PPM patients. The longer hospitalization time of the PPM patients shown in the results might be due to the their 
Table 5 Postoperative outcomes

\begin{tabular}{|c|c|c|c|c|}
\hline & total & PPM group & non-PPM group & $P$ \\
\hline Perioperative transfusion & $269(25.2 \%)$ & $47(24.9 \%)$ & $222(25.3 \%)$ & NS \\
\hline Ventilation time (hr) & $21(20-23)$ & $21(20-23)$ & $21(20-23)$ & NS \\
\hline Reintubation & $3(0.3 \%)$ & $0(0.0 \%)$ & $3(0.3 \%)$ & NS \\
\hline Duration of first time ICU & $72(72-96)$ & $72(72-96)$ & $72(72-96)$ & NS \\
\hline Reentering ICU & $2(0.2 \%)$ & $2(1.1 \%)$ & $0(0.0 \%)$ & NS \\
\hline Chest tube output (ml) & $545.88 \pm 365.82$ & $555.15 \pm 295.51$ & $543.87 \pm 379.47$ & NS \\
\hline Reoperation for bleeding & $18(1.7 \%)$ & $1(0.5 \%)$ & $17(1.9 \%)$ & NS \\
\hline Sternal wound infection & $3(0.3 \%)$ & $0(0.0 \%)$ & $3(0.3 \%)$ & NS \\
\hline Cerebral infarction & $5(0.5 \%)$ & $0(0.0 \%)$ & $5(0.6 \%)$ & NS \\
\hline Postoperative stroke & $1(0.1 \%)$ & $0(0.0 \%)$ & $1(0.1 \%)$ & NS \\
\hline Newly onset AF & $3(0.3 \%)$ & $0(0.0 \%)$ & $3(0.3 \%)$ & NS \\
\hline Mortality within 30 days & $9(0.8 \%)$ & $2(1.1 \%)$ & $7(0.8 \%)$ & NS \\
\hline Hospitalization expense (USD) & $\begin{array}{l}13,726 \\
(11632-16,030)\end{array}$ & $\begin{array}{l}14,446 \\
(12538-17,010)\end{array}$ & $\begin{array}{l}13,628 \\
(11509-15,775)\end{array}$ & 0.032 \\
\hline Length of stay (d) & 14(12-18) & 15(13-19) & 14(12-18) & 0.011 \\
\hline
\end{tabular}

ICU intensive care unit, $A F$ atrial fibrillation, $N S$ not significant

higher average age and because their recovery time might be longer than in younger patients. Also, the elevated hospitalization expense could be explained by higher price of the bioprosthesis which was more common in the PPM group.

\section{Clinical implication for east Asian population}

Currently, the most precise parameter in characterizing PPM is the EOAi [20], which is defined as the EOA of the prosthesis divided by the patient's BSA. EOAi is in fact the only parameter found to consistently correlate with the postoperative gradient; therefore it is the most widely used. In Western countries, the predominant cause of mitral valve disease is degenerative mitral valve regurgitation. For this population, patients with mitral valve diseases usually have a larger left ventricle volume (left ventricular diastolic diameter) than the eastern Asian population; therefore, implantation of a large size prosthesis to avoid PPM will not have an obvious effect on left ventricular function. Hence, the parameter of EOAi has high feasibility in characterizing PPM for Western populations.

However, in a rheumatic population such as the eastern Asian population, the incidence of mitral valve stenosis is

Table 6 Logistic regression model for postoperative 30-day global mortaliy

\begin{tabular}{lllll}
\hline Factors & mean or $\%$ & Odds ratio & $95 \% \mathrm{Cl}$ & $P$ value \\
\hline smoking history & $11.5 \%$ & 3.199 & $0.729-14.041$ & 0.004 \\
preoperative LVEF & 62.11 & 0.955 & $0.887-1.029$ & 0.001 \\
PPM & $17.7 \%$ & 1.138 & $0.226-5.743$ & 0.654 \\
\hline
\end{tabular}

Cl confidence interval, LVEF left ventricular ejection fraction much higher than mitral valve regurgitation [11]. A larger proportion of this population has small left ventricle size, with part of the patients' LVDd even smaller than the mitral annulus diameter. For these patients, implantation of a large sized prosthesis might compromise the effective cardiac muscular contraction of the left ventricle, causing

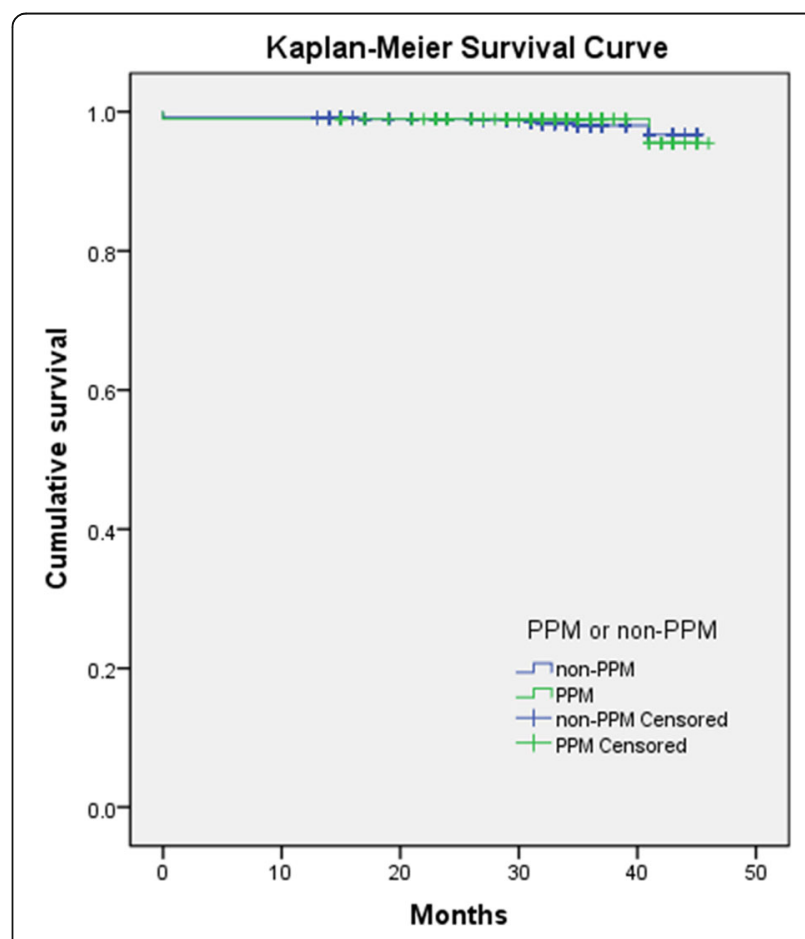

Fig. 4 Kaplan-Meier cumulative mid-term survival, Prosthesis-patient mismatch (PPM) vs non prosthesis-patient mismatch 
Table 7 Mid-term follow-up information

\begin{tabular}{lllll}
\hline & Total & PPM group & non-PPM group & $P$ value \\
\hline $\begin{array}{l}\text { Follow-up time } \\
\text { (months) }\end{array}$ & $31(23-35)$ & $32(24-35)$ & $31(23-33)$ & $P=0.362$ \\
$\begin{array}{l}\text { NYHA functional } \\
\text { class (III-IV) }\end{array}$ & $9.2 \%$ & $9.0 \%$ & $9.6 \%$ & $P=0.902$ \\
Mortality & $17(1.6 \%)$ & $3(1.6 \%)$ & $14(1.6 \%)$ & $P=0.994$ \\
\hline
\end{tabular}

NYHA New York Heart Association

left ventricular systolic dysfunction or, even worse, increase the risk of left ventricular rupture.

In our opinion, whether the current PPM standard is suitable for a rheumatic population such as the eastern Chinese is worth further exploration. Our results showed that there were no differences regarding the PPM occurrence of each valve size in the mechanical prosthesis. In our future study, we hope that we can explore a more precise parameter in predicting PPM then the current one, hence providing a more accurate prediction of patient outcomes for patients who underwent MVR in our population.

\section{Limitations of the study}

There are limitations of the study which must be recognized. First, this is a retrospective analysis, and, as an inherent disadvantage, the recorded differences in patient outcomes could have originated from smaller recorded or unrecorded differences between PPM and non-PPM patients. Second, in our study, EOA was predicted by reference tables, which might not reflect the actual in vivo values of the EOAi. Moreover, this is a single-centered short/mid-term study, and sample size and follow-up time were limited. Therefore, a randomized prospective multi-centered clinical trial with a long follow-up time is needed to study the effect of mitral PPM on longer-term patient outcomes.

\section{Conclusions}

Our results demonstrated that higher age, bioprosthesis, larger BSA and smaller left ventricle were associated with mitral PPM. However, PPM was not associated with poorer early outcomes after MVR surgery. In eastern China, the prevalence of mitral valve stenosis is high; therefore, whether the standard PPM criteria are suitable for patients of this district needs to be further verified.

\footnotetext{
Abbreviations

AF: Atrial fibrillation; AFRA: Atrial fibrillation radio frequency surgery; BMI: Body mass index; BSA: Body surface are; CABG: Coronary artery bypass grafting; $C A B G$ : Coronary artery bypass grafting; $\mathrm{Cl}$ : Confidence interval; CPB: Cardiopulmonary bypass; EOA: Effective orifice area; EOAi (iEOA): Effective orifice area index; ICU: Intensive care unit; LAD: Left atrial diameter; LVDd: Left ventricular diastolic diameter; LVEF: Left ventricular ejection fracture; LVESV: Left ventricular end-systolic volume; MR: Mitral valve regurgitation; MVR: mitral valve replacement; NS: Not significant; NYHA: New York Heart Association; OR: Odd ratio; PHM: Prosthesis-patient mismatch; PPM: Prosthesis-patient mismatch; SD: Standard deviation
}

\section{Acknowledgements}

The authors would like to thank the anesthetists, intensivists, heart surgeons, nursing staff, perfusionists and the laboratory department at the First Affiliated Hospital, Zhejiang University for the collection and management of the data presented in this report.

\section{Availability of data and materials}

The datasets during and/or analysed during the current study available from the corresponding author on reasonable request.

\section{Authors' contributions}

AA and JZ analyzed and interpreted the patient data, and wrote the paper. $\mathrm{HZ}$ and $\mathrm{YN}$ prepared the tables and figure, and were major contributors in writing the manuscript. JZ drafted the final manuscript. All authors read and approved the final manuscript.

Ethics approval and consent to participate

written informed consent waived by the Hospital Review Board.

\section{Consent for publication}

Not applicable.

\section{Competing interests}

The authors declare that they have no competing interests.

\section{Publisher's Note}

Springer Nature remains neutral with regard to jurisdictional claims in published maps and institutional affiliations.

Received: 14 May 2018 Accepted: 25 September 2018

Published online: 03 October 2018

\section{References}

1. Rahimtoola SH. The problem of valve prosthesis-patient mismatch. Circulation. 1978;58(1):20-4.

2. Rahimtoola SH, Murphy E. Valve prosthesis--patient mismatch. A long-term sequela. Br Heart J. 1981:45(3):331-5.

3. Hong S, Yi GJ, Youn YN, Lee S, Yoo KJ, Chang BC. Effect of the prosthesispatient mismatch on long-term clinical outcomes after isolated aortic valve replacement for aortic stenosis: a prospective observational study. J Thorac Cardiov Sur. 2013;146(5):1098-104.

4. Fuster RG, Montero Argudo JA, Albarova OG, et al. Patient-prosthesis mismatch in aortic valve replacement: really tolerable? Eur J Cardiothorac Surg. 2005:27(3):441-9 discussion 9.

5. Guo L, Zheng J, Chen L, et al. Impact of prosthesis-patient mismatch on short-term outcomes after aortic valve replacement: a retrospective analysis in East China. J Cardiothorac Surg. 2017;12(1):42.

6. Dumesnil JG, Honos GN, Lemieux M, Beauchemin J. Validation and applications of mitral prosthetic valvular areas calculated by Doppler echocardiography. Am J Cardiol. 1990;65(22):1443-8.

7. Dumesnil JG, Yoganathan AP. Valve prosthesis hemodynamics and the problem of high transprosthetic pressure gradients. Eur J Cardiothorac Surg. 1992;6(Suppl 1):S34-7 discussion S8.

8. Leavitt J, Coats MH, Falk RH. Effects of exercise on transmitral gradient and pulmonary artery pressure in patients with mitral stenosis or a prosthetic mitral valve: a Doppler echocardiographic study. J Am Coll Cardiol. 1991; 17(7):1520-6.

9. Rosenhek R, Binder T, Maurer G, Baumgartner H. Normal values for Doppler echocardiographic assessment of heart valve prostheses. J Am Soc Echocardiogr. 2003;16(11):1116-27.

10. Dumesnil JG, Pibarot P. Prosthesis-patient mismatch: an update. Curr Cardiol Rep. 2011;13(3):250-7.

11. Lee SH, Chang BC, Youn YN, Joo HC, Yoo KJ, Lee S. Impact of prosthesispatient mismatch after mitral valve replacement in rheumatic population: does mitral position prosthesis-patient mismatch really exist? J Cardiothorac Surg. 2017;12(1):88.

12. Lam BK, Chan $V$, Hendry $P$, et al. The impact of patient-prosthesis mismatch on late outcomes after mitral valve replacement. J Thorac Cardiovasc Surg. 2007;133(6):1464-73. 
13. Magne J, Mathieu P, Dumesnil JG, et al. Impact of prosthesis-patient mismatch on survival after mitral valve replacement. Circulation. 2007; 115(11):1417-25.

14. Li M, Dumesnil JG, Mathieu P, Pibarot P. Impact of valve prosthesis-patient mismatch on pulmonary arterial pressure after mitral valve replacement. J Am Coll Cardiol. 2005:45(7):1034-40.

15. Jamieson WR, Germann E, Ye J, et al. Effect of prosthesis-patient mismatch on long-term survival with mitral valve replacement: assessment to 15 years. Ann Thorac Surg. 2009;87(4):1135-41 discussion 42.

16. Aziz A, Lawton JS, Maniar HS, Pasque MK, Damiano RJ Jr, Moon MR. Factors affecting survival after mitral valve replacement in patients with prosthesispatient mismatch. Ann Thorac Surg. 2010;90(4):1202-10 discussion 10-1.

17. Angeloni $E$, Melina G, Pibarot $P$, et al. Impact of prosthesis-patient mismatch on the regression of secondary mitral regurgitation after isolated aortic valve replacement with a bioprosthetic valve in patients with severe aortic stenosis. Circ Cardiovasc Imaging. 2012;5(1):36-42.

18. Sakamoto H, Watanabe Y. Does patient-prosthesis mismatch affect longterm results after mitral valve replacement? Ann Thorac Cardiovasc Surg. 2010;16(3):163-7.

19. Shi WY, Yap CH, Hayward PA, et al. Impact of prosthesis--patient mismatch after mitral valve replacement: a multicentre analysis of early outcomes and mid-term survival. Heart. 2011:97(13):1074-81.

20. Pibarot P, Dumesnil JG. Prosthesis-patient mismatch: definition, clinical impact, and prevention. Heart. 2006;92(8):1022-9.

21. Bitar JN, Lechin ME, Salazar G, Zoghbi WA. Doppler echocardiographic assessment with the continuity equation of St. Jude Medical mechanical prostheses in the mitral valve position. Am J Cardiol. 1995;76(4):287-93.

22. Cohn LH, Edmunds LH. Cardiac surgery in the adult. 3rd ed. New York: McGraw-Hill Medical; 2008.

23. Borracci RA, Rubio M, Sestito ML, Ingino CA, Barrero C, Rapallo CA. Incidence of prosthesis-patient mismatch in patients receiving mitral Biocor(R) porcine prosthetic valves. Cardiol J. 2016;23(2):178-83.

Ready to submit your research? Choose BMC and benefit from:

- fast, convenient online submission

- thorough peer review by experienced researchers in your field

- rapid publication on acceptance

- support for research data, including large and complex data types

- gold Open Access which fosters wider collaboration and increased citations

- maximum visibility for your research: over $100 \mathrm{M}$ website views per year

At $\mathrm{BMC}$, research is always in progress.

Learn more biomedcentral.com/submissions 